\title{
Misconceptions Within the Use of Overall Equipment Effectiveness - A Theoretical Discussion on Industrial Examples
}

\author{
Marcus BENGTSSON ${ }^{\mathrm{a}, \mathrm{b}, 1}$, Lars-Gunnar ANDERSSON ${ }^{\mathrm{b}}$ and Pontus EKSTRÖM${ }^{\mathrm{b}}$ \\ ${ }^{a}$ School of Innovation, Design and Engineering, Mälardalen University, Sweden \\ ${ }^{\mathrm{b}}$ Operations, Volvo Construction Equipment, Sweden
}

\begin{abstract}
Overall equipment effectiveness (OEE) is a common performance measure used in manufacturing industry to identify and prioritize losses to perform improvement work on in order to increase the effectiveness of equipment. There exist challenges though, both in implementing OEE as well as in running an OEEprogram. Some of these challenges include lack of training and awareness, lack of focus, risk of misunderstanding the measure etc. This paper will deal with some of the possible misconceptions within the use of OEE that might arise during implementation or in continuously running an OEE-program. Some of the topics of misconceptions that will be discussed include: no financial issues are taken into consideration; that the factors of availability; performance and quality are not weighted; the connection to productivity is not always clear; the importance of cross-functionality of the measurement and work method; the issue of comparison of OEE results; and last but not least the view on and hunt for world class levels. The paper will discuss these (and some additional ones) theoretically and suggest some counter-actions so that they may be avoided.
\end{abstract}

Keywords. Overall Equipment Effectiveness, Misconceptions, Misuse, Challenges, Implementation

\section{Introduction}

Overall equipment effectiveness (OEE) is a commonly used performance measure in identifying and measuring losses to be reduced through improvement work in order to increase the effectiveness of equipment [1]. OEE, as a measure, is combining three measures in multiplying the factors of availability, performance, and quality. The result is a percentage value between 0 and $100 \%$ where 100 is perfect production with no disturbances or quality flaws performed in ideal cycle times.

To a large extent, the existing literature on OEE deal with the technical and methodological aspects of the measurement and work method, whereas less has been published on the challenges of implementing OEE [2]. However, researchers such as Sohal et al. [2], Ferko and Žnidaršič [3], and Binti Aminuddin et al. [4] through case studies and larger surveys have investigated some of the issues that might arise when implementing OEE and in running an OEE program. These include lack of management commitment and engagement, lack of training and awareness, lack of focus, and risk of misunderstanding the measure etc. Also, researchers such as Badiger et al. [5] and Cheah 
et al. [6] have pointed out that there is a lack of systematic approaches/frameworks to support and guide implementation efforts of OEE. Further, due to various reasons, OEE as a measure has been modified and developed to better fit contextualized situations and to expand in usability. For instance, Muchiri and Pintelon [7] explore several modifications that have taken its form in, for instance, total equipment effectiveness performance, production equipment effectiveness, overall factory effectiveness, and overall throughput effectiveness. Therefore, if a company is still using OEE according to the original definition, it is important to be aware of some shortcomings of the performance measure and the possible misconceptions it may lead to in order to avoid mistakes when implementing or in running an OEE program.

The purpose of this paper is to (from an industrial perspective) exemplify some misconceptions within the use of overall equipment effectiveness as a measurement and work method and to theoretically discuss these. The goal of the paper is to list and discuss counter-actions for these misconceptions so that they may be avoided by companies embarking on implementing OEE or improving its OEE processes. In the paper, we will, through industrial experience, exemplify misconceptions within the use of OEE, these have been structured and theoretically discussed.

We, the authors, have between us, roughly 80 years of experience in working within manufacturing industries, spread over departments like maintenance, production, and manufacturing engineering. All authors have worked with performance measures (OEE included) and improvement work in general. The misconceptions that will be broughtup in the paper will be accompanied by situations or issues that, over the years, have been witnessed in an industrial context by the authors. The situations and issues have, by the authors, been turned into quotes to serve as examples of misconceptions. The quotes are as such not real quotes made by persons, but made-up as a way of visualizing and exemplifying misconceptions within the use of OEE. These situations/issues and quotes have, by the authors, been discussed. The discussion has, for example, included why the situations/issues has originated and what to do to possibly reduce the risk for them to happen. The discussions, in turn, gave rise to the idea that the situations/issues might have already been discussed by others also. This idea initiated a literature search that gave rise to this paper. Keywords such as: overall equipment effectiveness; misconceptions; misuse; challenges; implementation; have been used in a broad search in books, scientific journals and conferences, and on the internet.

\section{Theoretical background}

The theory section will be divided into three sub-sections as follows: OEE as a measurement and improvement method, Implications when implementing OEE, and Modification and development of OEE as a measurement.

\subsection{OEE as a measurement and improvement method}

OEE was introduced by Nakajima [8] as a performance measure within the total productive maintenance (TPM) concept. The objective of the measure was to help maximizing equipment effectiveness by reducing six big losses: equipment failure, setup and adjustments, idling and minor stoppages, reduced speed, process defects, and reduced yield [8]. The OEE measure is calculated by multiplying the availability, performance, and quality measures of a machine or equipment, see Figure 1. For 
additional information on how to calculate OEE, see, for example, [7-11]. However, as discussed by Binti Aminuddin et al. [4] there are no accepted single definition on OEE. In both Dal et al. [9] and Jasiulewicz-Kaczmarek and Piechowski [12] it is pointed out that OEE can be used to monitor production, but it meets its real potential as a measure and method of improvement.

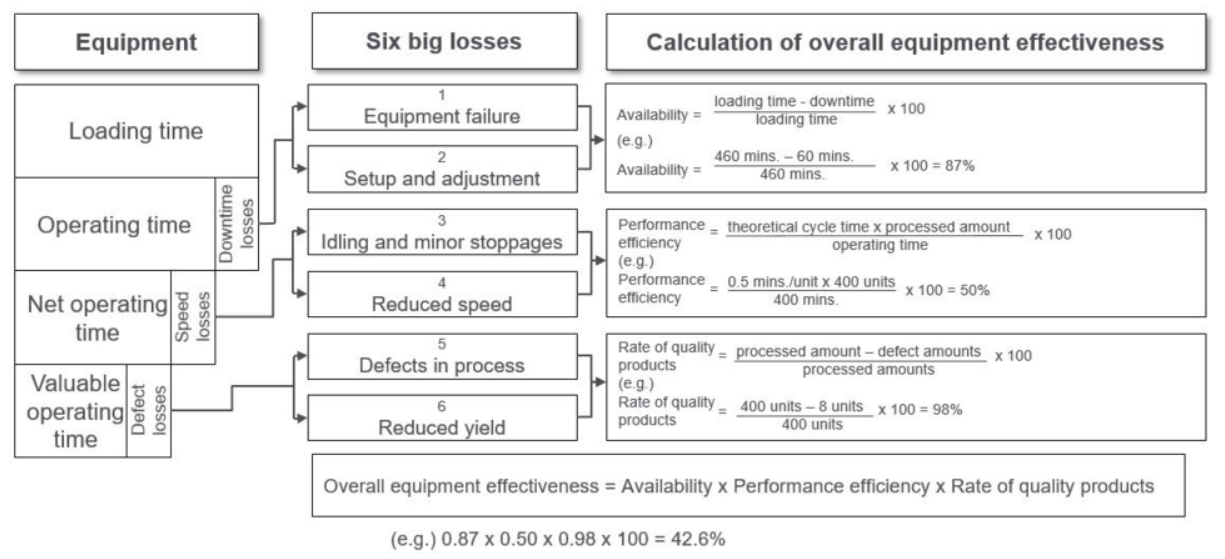

Figure 1. Overall equipment effectiveness explained by Nakajima [8].

Nakajima [8] means that companies employing TPM concepts can increase their effectiveness (measured by OEE) from $50 \%$ or lower up to $85 \%$ or higher. Shirose [13] however means that factories normally have OEE-values between 50-60\%. Supporting this, Ljungberg [14], reports on a study of 23 machine systems in the Swedish industry having an average OEE of 55\%. Ylipää et al. [15] report that study, performed with data from 2006 to 2012 on 98 companies in the Swedish industry, showed an average OEE of 51.5\%. Hedman et al. [16] report that a study, performed with data from October 2013 to March 2014 on 23 companies and more than 800 machines, showed a median OEE of $70 \%$, and an average OEE of $65 \%$. Though, there were variations between different industries; for instance, the food and beverage industry reported an average OEE of $74 \%$, whereas the automated discrete production industry had an average OEE of 59\% [16]. Nakajima [8] presents the following ideal conditions for OEE: availability is greater than $90 \%$, performance is greater than $95 \%$, and quality is greater than $99 \%$. This equals an OEE of $(0.90 \times 0.95 \times 0.99) 85 \%$, which is commonly referred to as the world class level [17]. Koch [18], however, similar to the abovementioned references, discuss OEE levels lower than these and explains that this is because of different ways of setting the OEE definitions, that is, what to count as losses. Ljungberg [14], for instance, states that the original definition of OEE [8] does not consider all the factors that reduce capacity utilization. Some of these include: planned downtime, lack of material, and lack of labor [14]. These, and some additional ones, are logged as losses by Koch [18]. De Ron and Rooda [19] also point out that it would be more appropriate to use the available time to calculate OEE and not, as suggested by Nakajima [8] the loading time. JasiulewiczKaczmarek and Piechowski [12] point out that there are three major concerns to the differences in OEE definitions, namely: the approach to loss definition, the intended implementation area (scope of measurement; single machine, production line or company wide), and specific characteristics on an industry. da Costa and de Lima [20] discuss additional misuses of OEE related to mistakes in cycle time consideration, using OEE to discuss capacity, and considering OEE for bottleneck identification. 


\subsection{Implications when implementing OEE}

Through a case study methodology, Sohal et al. [2] identify important aspects to consider when implementing OEE. These include: operator involvement, education and competence development, visibility and communication, simplicity in measurement processes, and top management engagement and commitment [2]. Further, Sohal et al. [2] also present challenges during the implementation phase: misunderstanding in the measurement process, lack of training in continuous improvement, challenge of changing the culture from one that focuses on production to one that focuses on waste elimination, and lack of goal setting [2]. Ferko and Žnidaršič [3] present some reasons as to why OEE implementation efforts fail, these include: management business strategy that does not drive OEE implementation, pre-implementation activities that are poorly planned, untrustworthy data due to poor use of the system support, and lengthy implementation procedures that cause missed deadlines. Through an international survey study, Binti Aminuddin et al. [4] discuss challenges when implementing OEE, including: inadequate training and awareness, lack of resources, lack of support from management, resistance from personnel, lack of focus, lack of experienced personnel, and lack of standardized systems for OEE calculations. Both Badiger et al. [5] and Cheah et al. [6] have suggested frameworks to support the implementation of OEE.

If one expands the view of and consider theories on the implementation of performance measurement systems in general, McCunn [21] has pointed out that many efforts within the implementation of, for instance, balanced scorecards fail. Neely and Bourne [22] argue a two-folded reason for this: (1) measurement systems are often poorly designed and (2) they are difficult to implement. According to Neely and Bourne [22], implementation difficulties may be clustered into three headings: political, infrastructural, and focus based. Bourne et al. [23] discuss the time perspective when implementing performance measurement systems and note that it can take several years before they are fully functional. Further, Bourne et al. [23], through a literature review, discuss some difficulties when implementing performance measurement systems. These include: lack of leadership and resistance to change, poorly defined metrics, significant time and expenses, goals that are negotiated rather than based on stakeholder requirements, and unrealistic goals [23].

\subsection{Modification and development of OEE as a measurement}

OEE has been modified and developed as a performance measure over several years into several different measures focusing on different areas. For instance, Muchiri and Pintelon [7] explore concepts such as total equipment effectiveness performance (TEEP), production equipment effectiveness (PEE), overall factory effectiveness (OFE), and overall throughput effectiveness (OTE). Also, Oliveira et al. [24] and Lanza et al. [25] summarize KPIs that are based on OEE. Koch [18] and Ivancic [26] explain TEEP, which is very close in definition to OEE but also takes into consideration planned downtime. $\mathrm{PEE}$ is another modification of OEE which weights the various losses accounted for [27]. Oechsner et al. [28] explore the development of OFE in where the aim is to measure not only the effectiveness of individual equipment but the entire factory. Muthiah and Huang [29] present OTE which, similar to OFE, takes the entire factory into consideration when calculating effectiveness but it also strives to perform factory-level diagnostics, such as bottleneck detection. OTE is calculated not from the perspective of time but rather on the perspective of produced parts [29]. Another development of increasing the scope of 
the OEE measure is taken by $[30,31]$ who present the concept of OEEML, overall equipment effectiveness of a manufacturing line.

Additional modifications and developments of OEE can be found. De Ron and Rooda [19] separate effectiveness (E) from OEE in that $E$ can be used for standalone equipment, whereas OEE should be used for integrated equipment. Garza-Reyes [32] presents the concept of overall resource effectiveness (ORE) as a complement to OEE, focusing on not only availability, performance, and quality but also material efficiency, process cost, and material cost variations. In [33-35], Wudhikarn presents another development of the OEE as the overall equipment cost loss, which considers both losses and their related costs. Braglia et al. [36] explore the development of overall material usage effectiveness (OME) that draws on the straightforward way of calculating OEE to address measuring the effective use of materials within a factory. Lastly, Keyser and Sawhney [37] discuss overall labor effectiveness (OLE) which is an extension of OEE where greater detail is put on labor losses, such as attendance, unavailability due to meetings, training, or other organizational functions, correct skill levels of scheduled employees etc.

\section{Misconceptions within the use of OEE}

Due to various shortcomings of OEE as a performance measure, as well as a need to contextualize the use of OEE as a measure, it has, as explained above, undergone significant modifications and developments. Therefore, if a company is still using OEE according to the original definition, it is important to be aware of these shortcomings to avoid misconceptions and, by those misconceptions, make mistake in an OEE program. Also, as mentioned in Section 1.2 some challenges that exists when implementing OEE deals with misunderstandings. Some of these possible misunderstandings and misconceptions will be exemplified and discussed below.

\subsection{The productivity issue}

Heard in industry - "We cannot keep working on reducing our cycle time anymore as it reduces our OEE-value”, these types or similar statements actually exist in industry. The statement does not only exemplify a problematic notion of measuring productivity by OEE alone but also a more rooted lack of awareness and understanding of OEE as a measurement and work method. More exemplification of these will follow in the rest of the paper.

OEE does not have a clear connection to productivity. If it did, it might as well be called overall equipment productivity and not overall equipment effectiveness. OEE does not, for instance, consider financial issues (see below) and as such does not reflect on efficiency or resources used to a high degree (see further [18, 38]). Though, if OEE is increased through the reduction of losses, productivity might also increase. However, this is connected with how the freed-up time is spent and whether there is increased production (that does not build stock [39]) or if a shift has been reduced. (For more information on unfruitful improvements, see [40].)

Being uncareful with input values to the OEE calculation, for instance through manipulation of cycle times [39] (i.e. increasing them), the OEE-value might increase while the actual productivity might decrease. Previous studies have presented performance rates on $100 \%$ [16] and even beyond $100 \%[14,15]$ indicating that the 
process is run in faster cycle times than the stipulated cycle time. Improving (or reducing) cycle time without adding production or reducing other wastes will instead decrease the OEE-value [41] while keeping productivity at status quo or even increasing productivity.

To address this issue, it is recommended to combine OEE with a clear productivity measure on input/output or manufacturing cost [41, 42].

\subsection{The financial issue}

Heard in industry - "OEE-levels must be improved at any cost". Sometimes it seems as it is the OEE-value, the percentage figure itself, that is most important, not the improvements it can generate.

OEE does not consider finances and how different methods of improvement affect financial measures [43]. For instance, increasing batch sizes to reduce setup time as a possible improvement may have a positive effect on OEE but at the same time a negative effect on financial measures as work-in-progress will increase [18]. In addition, OEE does not consider the number of employees running a process [44]. Therefore, maximizing OEE is not always justifiable $[45,46]$; there might be other, more financially sound, improvements to consider.

To address this issue it is, as explained above, recommended to combine OEE with other measures and work methods. In various forms, it is also recommended to use business case calculations, such as return on investment, to find out the most financially beneficial solutions.

\subsection{The unweighting of the factors issue}

Heard in industry - "All improvements are equally important". Improvement work is of course a prerequisite for any industrial company to survive on a competitive global market and from an ideological viewpoint all improvements are probably equally important in order to increase engagement in the workforce. However, when there is a need to prioritize between different improvement suggestions to spend resources on, weighting of the different suggestions becomes important.

In OEE, there is no weighting among availability, performance, and quality: an increase of $1 \%$ in quality is generally worth much more than a $1 \%$ increase in availability or performance [27, 33-35, 43, 46, 47]. As OEE measure losses in the form of time and not cost this could imply a problem when prioritizing improvement areas. OEE is also not a statistically valid measure $[45,47]$. As an example, consider us looking at daily OEE measurements of the same machine: if it amounts to $53 \%$ on both days, is that equally good or bad? If day one had an availability of $80 \%$, performance of $70 \%$, and quality of $95 \%$, and the second day had an availability of $70 \%$, performance of $95 \%$, and quality of $80 \%$, the OEE calculations are the same but the cost of lesser quality may be much higher on the second day [18].

Similar to the above issue, this issue to a great amount deals with financial calculations. If this is a major issue one might look into the modifications of OEE and actually start using a measure which takes weighting into consideration.

\subsection{The generalizability issue}

Heard in industry - "The best machine on the site delivers OEE-values at $88 \%$ - you need to increase OEE on this particular machine to the same level!" People that are 
unknowledgeable in OEE are often rather quick to draw conclusion from generalizations and comparisons between different machines expecting all machines to have the same prerequisites and thusly the same possibility of a high OEE-value.

OEE, though, is generally not a good indicator for comparison between companies or even machines $[16,18,45]$, because there are too many variables to consider. Comparing machines with different product-mix profiles (high-volume/low-mix operations vs. low-volume/high-mix operations) is like comparing apples with oranges [48]. Also, different companies use slightly different definitions of what is a loss within OEE and what is not. Some companies even have different definitions within the companies. However, the results from day to day, week to week, or month to month of the same piece of equipment can be compared unless, for instance, major changes in OEE loss definitions has been performed, if new production articles has been introduced or if production articles has been removed, or if other major changes has been implemented, such as changed ideal cycle time. Similarly, OEE is not a good measure for overall analysis; it is, however, suitable for machine-level analysis [45, 46, 48]. It should be noted that, often, OEE is not only measuring individual equipment effectiveness as it is affected by surrounding environment such as material handling, buffers, and ques $[16,17]$. This of course varies depending on the definition of losses.

The fact that it, in many cases, is not wise to compare OEE results is to a large extent a knowledge and awareness issue. As brought-up by Binti Aminuddin et al. [4] as a challenge in implementing OEE, inadequate training and awareness of OEE is a problem. One exercise that could increase awareness on this issue is to run a workshop in where actual theoretical maximum OEE results are calculated for specific equipment. Further, Bengtsson [49] exemplifies how a training and awareness exercise of OEE could be executed through game-based learning.

\subsection{The cross-functionality issue}

Heard in industry - "Maintenance is responsible for OEE". Or any other function for that matter. It is common to hear that some function have been given the responsibility of OEE. It could not be further from the reality of it.

OEE is not an indicator of maintenance effectiveness [45]. Even though OEE was developed from the TPM concept, it spans many other areas of a factory; therefore, it is unfair to say that it is a maintenance measure. A maintenance department or a particular maintenance action might have a significant impact on OEE results, but so does many other support functions and their activities also. Bamber et al. [10], for instance, discuss that it is necessary to address all six big losses in manufacturing by using cross-functional teams; only through this method of using combined skills and knowledge will a company be able to determine counter-actions for the logged losses. Badiger et al. [5] also stress the importance of using cross-functional teams when working with OEE. Andersson and Bellgran [50] stress the importance of active involvement of support functions, such as production engineering and maintenance, to increase the level of improvements as well as the speed of change. Also, Jasiulewicz-Kaczmarek and Piechowski [12] state that OEE is a useful guide for production managers to work with improvement and in increasing cooperation with internal functions such as production, maintenance, and logistics. Depending on the loss definition, more or less all functions in a production facility affects the OEE results in one way or another. Some are maybe more obvious than others, such as production, maintenance, and logistics. But also, for example, purchasing departments through, for instance, issues with bad material and human resource departments through, 
for instance, issues of competence development or shift strategies are influencing the OEE. This is basically a maturity issue and can be solved with training and awareness exercises.

\subsection{The issue of excessive reliance on OEE as a sole measurement}

Heard in industry - "As we measure OEE we do not need to follow other performance measures". In industry there can sometimes be an over-trust in OEE in that OEE will capture everything.

OEE is not a complete manufacturing performance measurement system and it is not just a matter of balancing OEE and some other productivity measures, depending on the context there might be additional important measures to follow. OEE does not measure, for instance, the strategy, flow orientation, and external effectiveness to a significant extent [17]. The effectiveness of a factory's production depends on the effective use of not only its equipment but also its materials, labor, and methods [51] in [32]. Binti Amuniddin et al. [4], through their survey, also find that OEE is not the only measure used to identify improvement activities. Examples of other measures include cost, quality incidents, dependability, flexibility, and employee morale [4]. Dal et al. [9] also stress that OEE should not be the sole performance measure but should be balanced with more traditional measures. Also, OEE as a lean tool and measure should not be used in isolation and measures, such as: asset utilization, productivity, reliability, and total cost of ownership should also be used in decision-making [52]. This issue can be solved by using other measures that complement OEE, such as, measures following-up productivity and employee engagement.

\subsection{The issue of over-trusting automatic follow-up systems}

Heard in industry - "Garbage in-garbage out, we need an automatic follow-up system so that we can trust the data". In industry there seems to be trust issues with manual follow-up systems and we have even seen examples of improvement paralysis due to the fact that managers do not trust the data.

Regarding the issue of manual or automated OEE measurement system, Jonsson and Lesshammar [17] state that: "The data collection should be at such detailed level that it fulfils its objectives without being unnecessarily demanding of resources" (p.63). Ferko and Žnidaršič [3] and Dal et al. [9], however, stress that inaccurate data will lead to lack of credibility, and, therefore, it is important to invest time into the data collection process. Muchiri and Pintelon [7] mean that manual data collection, while being low in cost, has low data accuracy; contrarily, automatic data collection is high in cost, but its data accuracy is higher and the data-collection process is simplified. A good point is made in Hedman et al. [16], referring to Saenz de Ugarte et al. [53], who, in their turn, refer to Jones et al. [54], where it is stated that: “...technology can assure the availability of data but not guarantee that the data is accurate.” (p.128). Further, Hedman et al. [16] report on a study where a large dataset of OEE measurements (23 companies and 884 machines over a six-month period) were analyzed. All measurements were performed with the same system for measurement of OEE. Even though the system was semi-automated, $19 \%$ of the scheduled production time was categorized as unclassified losses. Hedman et al. [16] conclude their study by stating: "It has been found that when the measurement is automated, it is even more important that companies do not distance themselves from managing the detailed characteristics of their manufacturing process. " (p. 132). 
As with many other work methods it is good to start with a basic process and to master it well before increasing the efficiency of said process with tools of digitalization (see further [55]). A first step is of course for companies to clearly state the objective of an OEE program. If the objective of a particular point in time is not very wide, implementing an automatic follow-up system may be exaggerated. One should not implement an automated follow-up system unless there truly is a need for it. Solving the issue of trust with manual OEE data deals a lot with management issues in following-up measurements and in being engaged and committed. If a loss chart is not trusted one does not have to start with improvement initiatives on the losses that are not trusted, go to the second loss on the chart, or third or even fourth. One might not even have to work with a particular loss at all but might instead use ones attention in increasing stability or if the measurement process (input of losses) is not stable - focus to improve it. Not starting any improvement initiative at all due to trust issues of the data (if, for instance, an increase of utilization or stability is needed) is truly a waste.

\subsection{The world class issue}

Heard in industry - "As our goal is to be world class we need to have an OEE-level of $85 \%$ or above". This situation has been witnessed quite often by the authors. As stated above, sometimes it seems as it is the OEE-value itself that is valued most important and not what it may lead to in terms of improvements.

As previously stated, Nakajima [8] presents the following ideal conditions for OEE: availability is greater than $90 \%$, performance is greater than $95 \%$, and quality is greater than $99 \%$. This equals an OEE of $85 \%$, which is commonly referred to as the world class level [17]. Empirical studies though, such as [14-16, 18], visualizes that OEE levels in industry in general is a lot lower. The variation of OEE scores often depend on varying processes, industries, equipment, and operational requirements [50]. Some equipment do not even have the possibility of operating with an OEE as high as $85 \%$ due to various restricting factors in, for instance, production design causing blocking or starvation and high-mix production causing losses in setup time etc. In reference to judging something as being world class only by a certain level, Koch [18] discusses stability as one form of world class and means that if an equipment can be run with a stable OEE day after day it is a first step in being world class, regardless of whatever level.

This issue can, as many others, be mitigated with training and awareness. Also, this issue can be solved by simulating the theoretical maximum OEE result for a specific equipment. Also, instead of management asking for a certain OEE result they should ask for stability first and then a steady increase of the OEE results (if needed).

\section{Discussions}

Using OEE as a performance measure in identifying and measuring losses to be reduced through improvement work is a common approach, and indeed, if handled correctly, an efficient way forward for industrial companies. However, implementing and running an OEE-program is not an easy task. There are several challenges. Some of these challenges are mentioned above. Also, OEE as a measure has undergone several modifications and developments in recent years. These two issues, challenges in implementation and in running an OEE-program and modifications to the measure itself has opened up for a multitude of possible misconceptions. These misconceptions can, if companies are not 
aware of them, create mistrust towards an entire OEE-program and can be the reason why an implementation or an existing program fails. In this paper we have exemplified some of these misconceptions from an industrial point of view, discussed them theoretically and exemplified possible counter-actions to reduce their destructive force.

One issue that has not been brought-up in the paper thus far is brought-up by Ljungberg [14] who states that much of the OEE data are never compiled or analyzed at all. This is, perhaps, an issue more related to management than misconceptions. However, it is important to bring it up as it too will increase the risk of failing with an OEE-program.

This paper is not aiming at giving a complete list of misconceptions. The misconceptions brought-up in the paper should be seen as examples though. There could of course be many more. In some companies, many of these exemplified misconceptions might be recognized while in other companies, very few or none of the exemplified misconceptions will be recognized. This has probably to do with maturity and awareness. A company with a mature OEE-process with educated, aware, and dedicated employees should suffer less from misconceptions than companies with immaturity issues. On the other hand, a company with a mature OEE-process might be more open-minded and inclined to admit problems and possible misconceptions in their processes compared to companies with immaturity issues. Anyhow, being aware of misconceptions is something that companies are encouraged to work on in order for them to increase its use of OEE as a measure in their improvement program.

Future work would benefit from inclusion of empirical studies in form of, either or both, survey studies and in-depth interview studies covering some, or all, of the misconceptions discussed in this paper and possibly additional ones. A richer empirical material would in a better way, than what has been possible in this paper, explain how misconceptions within the use of OEE might come about and also how they may be avoided. A richer empirical material might also help to structure the misconceptions discussed in this paper in another way, which might increase the visualization in a more pedagogical way. A case study approach studying one or, even better, several companies would also make for an interesting empirical material on the topic. Lastly, the literature search could also be improved if turned into a structured literature review instead.

\section{Acknowledgement}

The research work is a part of the initiative for Excellence in Production Research (XPRES).

\section{References}

[1] U. Kumar, D. Galar, A. Parida., C. Stenström and L. Berges, Maintenance performance metrics: a state of the art review, Journal of Quaility in Maintenance Engineering, Vol. 19 Iss. 3, 2013, pp. 233-277.

[2] A. Sohal, J. Olhager, P. O’Neill and D. Prajogo, Implementation of OEE-issues and challenges, In: Competitive and sustainable manufacturing products and services, Milano, 2010, pp. 1-8.

[3] R. Ferko and A. Žnidaršič, Using OEE Approach for Improving Manufacturing Performance, Informacije Midem-Ljublana, Vol. 37 No.2, 2007, pp. 105-111.

[4] N.A. Binti Aminuddin, J.A. Garza-Reyes, V. Kumar, J. Antony and L. Rocha-Lona, An analysis of managerial factors affecting the implementation and use of overall equipment effectiveness, International Journal of Production Research, Vol. 54 No. 15, 2016, pp. 4430-4447.

[5] A.S. Badiger, R. Gandhinathan and V.N. Gaitonde, A methodology to enhance equipment performance using the OEE measure, European journal of industrial engineering, Vol. 2 No. 3, 2008, pp. 356-376. 
[6] C.K. Cheah, J. Prakash and K.S. Ong, Overall equipment effectiveness: a review and development of an integrated improvement framework, International Journal of Productivity and Quality Management, Vol. ahead-of-print No. ahead-of-print, (in press).

[7] P. Muchiri and L. Pintelon, Performance measurement using overall equipment effectiveness (OEE): literature review and practical application discussion, International Journal of Production Research, Vol. 46 No. 13, 2008, pp. 3517-3535.

[8] S. Nakajima, Introduction to TPM: Total Productive Maintenance, Productivity Press, Inc., Cambridge, Massachusetts, 1988.

[9] B. Dal, P. Tugwell and R. Greatbanks, Overall equipment effectiveness as a measure of operational improvement - A practical analysis, International Journal of Operations \& Production Management, Vol. 20 No. 12, 2000, pp. 1488-1502.

[10] C.J. Bamber, P. Castka, J.M Sharp and Y. Motara, Cross-functional team working for overall equipment effectiveness (OEE), Journal of Quality in Maintenance Engineering, Vol. 9 Iss. 3, 2003, pp. 223-238.

[11] P. Gupta and S. Vardhan, Optimizing OEE, productivity and production cost for improving sales volume in an automobile industry through TPM: A case study, International Journal of Production Research, Vol. 54 No. 10, 2016, pp. 2976-2988.

[12] M. Jasiulewicz-Kaczmarek and M. Piechowski, Practical Aspects of OEE in Automotive Company Case Study, In: Proceedings of the 2016 International Conference on Management Science and Management Innovation, Guilin, China, 2016 ,pp. 213-218.

[13] K. Shirose, TPM for Workshop Leaders, Productivity Press, Inc., Cambridge, Massachusetts, 1992.

[14] Ö. Ljungberg, Measurement of overall equipment effectiveness as a basis for TPM activities, International Journal of Operations \& Production Management, Vol. 18 Iss. 5, 1998, pp. 495-507.

[15] T. Ylipää, A. Skoogh, J. Bokrantz and M. Gopalakrishnan, Identification of maintenance improvement potential using OEE assessment, International Journal of Productivity and Performance Management, Vol 66 No. 1, 2017, pp. 126-143.

[16] R. Hedman, M. Subramaniyan and P. Almström, Analysis of critical factors for automatic measurement of OEE, Procedia CIRP, Vol. 57, 2016, pp. 128-133.

[17] P. Jonsson and M. Lesshammar, Evaluation and improvement of manufacturing performance measurement systems - The role of OEE, International Journal of Operations \& Production Management, Vol. 19 No. 1, 1999, pp. 55-78.

[18] A. Koch, 2003, OEE Industry Standard, version 2, Blom Consultancy, Accessed 14.02.2019. [Online]. Available: https://tpm4u.files.wordpress.com/2010/10/oee-industry-standard-v2.pdf.

[19] A.J. De Ron and J.E. Rooda, OEE and equipment effectiveness: An evaluation, International Journal of Production Research, Vol. 44 No 23, 2006, pp. 4987-5003.

[20] S. da Costa and E. de Lima, Uses and Misuses of the 'Overall Equipment Effectiveness' for Production Management, In: IEEE International Engineering Management Conference, Cambridge, 2002.

[21] P. McCunn, The balanced scorecard: The eleventh commandment, Management Accounting: Magazine for Chartered Management Accountants, Vol. 76 No. 11, 1998, pp. 34-36.

[22] A. Neely and M. Bourne, Why measurement initiatives fail, Measuring Business Excellence, Vol. 4 No. 4, 2000, pp. 3-7.

[23] M. Bourne, A. Neely, J. Mills and K. Platts, Implementing performance measurement systems: A literature review, International Journal of Business Performance Management, Vol 5, 2003, pp. 1-24.

[24] R. Oliveira, S.A. Taki, S. Sousa, and M.A. Salimia, Global Process Effectiveness: When Overall Equipment Effectiveness Meets Adherence to Schedule, In: $29^{\text {th }}$ International Conference on Flexible Automation and Intelligent Manufacturing, Limerick, Ireland, 2019.

[25] G. Lanza, J. Stoll, N. Stricker, S. Peters and C. Lorentz, Measuring Global Production Effectiveness, In: $46^{\text {th }}$ CIRP Conference on Manufacturing Systems, Sesimbra Portugal, 2013.

[26] I. Ivancic, Development of maintenance in modern production, In: Euromaintenance'98 Conference Proceedings, Dubrovnik/Hrvatska, 1998, pp.5-7.

[27] A. Raouf, Improving capital productivity through maintenance, International Journal of Operations \& Production Management, Vol. 14 No. 7, 1994, pp. 44-52.

[28] R. Oechsner, M. Pfeffer, L. Pfitzner, H. Binder, E. Müller and T. Vonderstrass, From overall equipment efficiency (OEE) to overall Fab effectiveness (OFE), Materials Science in Semiconductor Processing, Vol. 5 No. 4-5, 2002, pp. 333-339.

[29] K.M.N. Muthiah and S.H. Huang, Overall throughput effectiveness (OTE) metric for factory-level performance monitoring and bottleneck detection, International Journal of Production Research, Vol. 45 No. 20, 2007, pp. 4753-4769.

[30] M. Braglia, D. Castellano, M. Frosolini and M. Gallo, Integrating considerations of uncertainty within the OEE of a manufacturing line, International Journal of Industrial and Systems Engineering, Vol. 32 No. 4, 2019, pp. 469-496. 
[31] M. Braglia, M. Frosolini and F. Zammori, Overall equipment effectiveness of a manufacturing line (OEEML) An integrated approach to assess systems performance, Journal of Manufacturing Technology Management, Vol. 20 No. 1, 2008, pp. 8-29.

[32] J.A. Garza-Reyes, From measuring overall equipment effectiveness (OEE) to overall resource effectiveness (ORE), Journal of Quality in Maintenance Engineering, Vol. 21 No. 4, 2015, pp. 506-527.

[33] R. Wudhikarn, Overall weighting equipment effectiveness, In: The IEEE International Conference on Industrial Engineering and Engineering Management (IEEM), Macau, 2010.

[34] R. Wudhikarn, Improving overall equipment cost loss adding cost of quality, International Journal of Production Research, Vol 50 No. 12, 2012, pp. 3434-3449.

[35] R. Wudhikarn, Implementation of the overall equipment cost loss (OECL) methodology for comparison with overall equipment effectiveness (OEE), Journal of Quality in Maintenance Engineering, Vol 22 No 1, 2016, pp. 81-93.

[36] M. Braglia, D. Castellano, M. Frosolini and M. Gallo, Overall material usage effectiveness (OME): a structured indicator to measure the effective material usage within manufacturing process, Production Planning \& Control, Vol. 29 No. 2, 2018, pp. 143-157.

[37] R.S. Keyser and R.S. Sawhney, Reliability in lean systems, International Journal of Quality \& Reliability Management, Vol. 30 No. 3, 2013, pp. 223-238.

[38] S. Tangen, Demystifying productivity and performance, International Journal of Productivity and Performance Management, Vol. 54 No. 1, 2005, pp.34-46.

[39] D. Van Goubergen, OEE: The Good, the Bad and the Ugly (Lean and OEE) (Presentation Supporting Paper). In: IIE Annual Conference. Proceedings, Institute of Industrial and Systems Engineers (IISE), 2010.

[40] M. Bengtsson and C. Osterman, Improvements in vain - the 9th waste, In: The 6th International Swedish Production Symposium, Göteborg, 2014.

[41] C. Andersson and M. Bellgran, On the complexity of using performance measures: Enhancing sustained production improvement capability by combining OEE and productivity, Journal of Manufacturing Systems, Vol. 35, 2015, pp. 144-154.

[42] P. Gupta and S. Vardhan, Optimizing OEE, productivity and production cost for improving sales volume in an automobile industry through TPM: a case study, International Journal of Production Research, Vol. 54 No. 10, 2016, pp. 2976-2988.

[43] M. Pophaley, Revisiting OEE as an assessment methodology for TPM activities: A practical analysis, IUP Journal of Operations Management, Vol. 9, 2010, pp. 35-42.

[44] P. Petersson, Process efficiency and capacity flexibility, PhD diss., Linköping University Sweden: Department of Mechanical Engineering, 2000.

[45] R.M. Williamson, 2006, Using overall equipment effectiveness: The metric and the measures. Accessed 05.10.2018. [Online]. Available: https://swspitcrew.com/wp-content/uploads/2018/01/OEE.pdf

[46] J. Bokrantz, A. Skoogh, T. Ylipää and J. Stahre, Handling of production disturbances in the manufacturing industry, Journal of Manufacturing Technology Management, Vol. 27 No. 8, 2016, pp. 1054-1075.

[47] S.S. Sonigra and M.N. Qureshi, Computation of Overall Equipment Effectiveness in Connecting Rod Manufacturing Opeations, The IUP Journal of Mechanical Engineering, Vol. VII No. 3, 2014, pp. 49-60

[48] U. Pabon, 2010, The 15 most common mistakes in lean implementation, Accessed 05.10.2018. [Online]. Available:http://www.qbsteam.com/clientuploads/QBS\%20WHITEPAPER\%20The\%2015\%20Most\% 20Common\%20Mistakes\%20in\%20Lean\%20Implementations.pdf

[49] M. Bengtsson, Using a game-based learning approach in teaching overall equipment effectiveness, Journal of Quality in Maintenance Engineering, Vol. ahead-of-print No. ahead-of-print, 2019.

[50] C. Andersson and M. Bellgran, Managing Production Performance with Overall Equipment Efficiency (OEE) - Implementation Issues and Common Pitfalls, In: The 44th CIRP Conference on Manufacturing Systems, Madison, 2011.

[51] T. Suzuki, TPM in Process Industries, Productivity Press: Portland, Oregon, 1999.

[52] Idhammar (Whitepaper), 2010, Implementing OEE Systems: Delivering on the Promise: Best Practices for Continuous Improvement, Accessed 01.11.2019. [Online]. Available: https://www.idhammarsystems.com/wp-content/uploads/2019/04/Idhammar_OEE_Best-PracticeImplementation_Whitepaper.pdf

[53] B. Saenz de Ugarte, A. Artiba and R. Pellerin, Manufacturing execution system - a literature review, Production Planning and Control, Vol. 20 No. 6, 2009, pp. 525-539.

[54] A. Jones, L. Reeker and A. V. Deshmukh, On information and performance of complex manufacturing systems, In: Manufacturing Complexity Network Conference, Cambridge, 2002.

[55] M. Bengtsson, and G. Lundström, On the importance of combining "the new" with "the old" - One important prerequisite for maintenance in Industry 4.0, In: Proceedings of the $8^{\text {th }}$ Swedish Production Symposium, SPS2018, Stockholm, Sweden, 2018. 